\title{
Hypoglycemic Effet Of Some Fluoroquinolones On Normal And Diabetic Experimental Animals
}

\author{
*Amr Heshmat Rostom \& ** Ali Ibrahim Al-Sultan \\ * Department Pharmacology, ** Department Internal Medicine. \\ College of Medicine, Al Hasa, King Faisal University.
}

\begin{abstract}
Background:Fluoroquinolones are among the anti-microbial that have widespread use for treatment of community- and hospital-acquired infections. Although uncommon, hypoglycemia has been reported with some fluoroquinolones and appears to occur most frequently in elderly patients with type 2 diabetes mellitus who were receiving therapy with oral hypoglycemics. The clinical data emerged suggest that the fluoroquinolones can affect glucose homeostasis through an unknown mechanism. The present work aimed to explore the potential effects of some fluoroquinolones on glucose metabolism and blood glucose level in experimental animals. Two fluoroquinolones (gatifloxacin, moxifloxacin) were used in the present study using different rabbit groups; normal and experimentally diabetic. Dug interaction with anti-diabetic drugs was also investigated. Safety considerations were our goal.

Materials And Method: In the present work, alloxan (100 $\mathrm{mg} / \mathrm{kg}$ body weight 3 successive doses, intraperitonially) was used to induce diabetes in experimental animals. The blood glucose level after alloxan was measured. Oral anti-diabetics glimepiride, rosiglitazone, and metformin produced significant lowering effect on blood glucose level in normal and diabetic animals. Gatifloxacin and moxifloxacin were similar in producing lowering of blood glucose level in non diabetic and diabetic animals and significantly potentiated the hypoglycemic action of oral anti-diabetics in the alloxan diabetic rabbits.
\end{abstract}

Keywords: Oral anti-diabetics Glimepiride, Rosiglitazone, Metformin, Fluoroquinolones (Gatifloxacin and Moxifloxacin) Alloxan and diabetes mellitus.

\section{Introduction}

A variety of medications has been associated with hypoglycemia, and the list of these medications is expanding. Fluoroquinolones are generally regarded as safe antimicrobial agents with relatively few adverse effects or drug interaction (Basaria et al., 2002).

The World Health Organization (WHO) recognized type 2 diabetes and obesity as a global health problem that has reached epidemic proportion (WHO, 1997). Diabetes mellitus is one of the most common diseases in the world; it was estimated that 150 million patients suffered from diabetes mellitus in the year 2000 (Buse, 2000), and that number may reach 300 millions in the year 2025 (Zimmet, 2003).
Many drugs produce a hypoglycemic state in normal and diabetic persons by different mechanisms of action. Some of them are used mainly for this therapeutic effect like sulfonylureas, metformin and rosiglitazone (Harrower, 1996 , Buse, 2000, and Harrigan et al., 2001). Other agents intensify the hypoglycemic action of oral hypoglycemics such as chloramphenicol (Brunova et al., 1977), tetracycline (Basaria et al, 2002), erythromycin (Petrakis et al., 1999), clarithromycin (Bussing and Gende, 2002), isoniazid (Ovali et al., 2004), and rifampicin (Niemi et al., 2001b).

Alloxan hyperglycemic effect is due to partial or total necrosis of beta cells which is presented histopathologically by 


\section{Hypoglycemic Effet Of Some Fluoroquinolones On........}

degeneration and nuclear pykinosis (Szkudelski et al., 1998). Alloxan exerts its diabetogenic action when it is administered parenterally: intravenously, intraperitoneal or subcutaneously. The dose of alloxan required for inducing diabetes depends on the animal species, route of administration and nutritional status (Szkudelski, 2001). When alloxan is given intraperitonealy or subcutaneously its effective dose must be 2-3 times higher than the intravenous dose. An intraperitonial dose below $150 \mathrm{mg} / \mathrm{kg}$ body weight may be insufficient for inducing diabetes. Fasted animals are more susceptible to alloxan, whereas, increased blood glucose provides partial protection (Bansal et al., 1980, Szkudelski et al., 1998).

Fluoroquinolones such as ciprofloxacin, levofloxacin, moxifloxacin and gatifloxacin are widely used for the treatment of bacterial infections. Fluoroquinolones-induced adverse effects have been reported to occur with increased frequency in the elderly, but large trials comparing the tolerability in aged and young individuals are still not available (Stallman and Lode, 2003). Despite their widespread use for the treatment of community- and hospital-acquired infections. Uncommon hypoglycemia has been reported with all the fluoroquinolones and appears to occur most frequently in elderly patients with type 2 diabetes mellitus who are receiving therapy with oral hypoglycemics. The exact mechanism of this effect is unknown, but it is postulated to be a result of blockage of adenosine 5'-triphosphate-sensitive potassium channels in pancreatic beta-cell membranes (Gavin et al., 2004, Friedrich and Dougherty, 2004). It was reported that patients receiving oral hypoglycemic agents are at greater risk of experiencing gatifloxacin-induced hypoglycemia than patients not receiving these agents. Clinicians should be aware of this potentially life-threatening adverse event and monitor blood glucose levels in all patients receiving concomitant oral hypoglycemic agents and gatifloxacin (LeBlanc and Cossette, 2004). Gatifloxacininduced hypoglycemia may persist for 24 hours after stoppage of the drug (Baker and Hangii, 2002).
Glimepiride, a hypoglycemic sulfonylurea drug causes reduction of blood glucose level predominantly via stimulation of insulin release from pancreatic $\beta$ cells. In addition, during long-term treatment, an insulinindependent blood glucose decreasing mechanism is assumed to operate (Gunter Muller, 2000). Mechanism of action of metformin is uncertain despite its known therapeutic benefits. Its mode of action appears to involve reduction of hepatic gluconeogenesis, decreased absorption of glucose from the gastrointestinal tract, and reduced insulin insensitivity (Zhou et al., 2001). Rosiglitazone is an anti-diabetic drug from the thiazolidinedione class, its mechanism of action is by activation of the intracellular receptor class of the peroxisome proliferator-activated receptors (PPARs), specifically PPAR $\gamma$ receptors. Rosiglitazone is a pure ligand of PPAR $\gamma$, and has no PPAR $\alpha$ - binding action. Apart from its effect on insulin resistance, it appears to have an anti-inflammatory effect. (Mohandy et al., 2004)

\section{Materials And Method}

\section{A) MATERIALS}

\section{Drugs and chemical agents}

1) Alloxan

Alloxan monohydrate (B.D.H., England): It is freely soluble in water.

2) Fluoroquinolones (gatifloxacin and moxifloxacin) were injected in dose of 20,40 , and $80 \mathrm{mg} / \mathrm{kg}$ body weight (bw) /day /rabbit intraperitonially.

3) Oral anti-diabetics glimepiride $(1.3 \mathrm{mg} /$ $\mathrm{Kg}$ bw /day /rabbit), rosiglitazone (1.3 $\mathrm{mg} / \mathrm{kg}$ bw /day /rabbit), and metformin (160 $\mathrm{mg} / \mathrm{Kg}$ bw /day /rabbit), were administered orally in different doses daily.

4) Intermediate acting insulin (Semilent insulin, Novo) injected subcutaneously at a dose of $0.5 \mathrm{U} / \mathrm{Kg} \mathrm{bw}$.

\section{1) Animals}

Male mixed breed rabbits weighing 1.8 - $2.5 \mathrm{Kg}$ were used in this study, animal food (pellet) and water were freely supplied. 
Animals were divided into 8 groups each of 8 rabbits.

Group 1: Served as control to study blood glucose level of control non-treated rabbits and after giving alloxan

Groups 2, 3, 4: Served to study the effect of oral anti-diabetics glimepiride, rosiglita-zone, and metformin, on blood glucose level in alloxanized diabetic rabbits.

Groups 5\&6: Served to study the effect of the fluoroquinolones (gatifloxacin and moxifloxacin) on blood glucose level in control non treated rabbits.

Group 7: Served to study the effect of the fluoroquinolones (gatifloxacin and moxifloxacin) on blood glucose level of alloxanized diabetic rabbits.

Group 8 (insulin treated): Served to compare the effect of the fluoroquinolones (gatifloxacin and moxifloxacin) with oral anti-diabetics glimepiride, rosiglitazone, and metformin, on blood glucose level of alloxanized diabetic rabbits, with insulin that was used as the standard hypoglycemic agent.

\section{B) Procedures and Method:}

\section{Induction of diabetes:}

Diabetes was induced by intraperitonial administration of alloxan monohydrate; $100 \mathrm{mg} / \mathrm{kg}$ body weight in a doses volume of 2ml. 2-3 successive doses, 2 days apart were given. The mentioned procedure produces type 2 diabetes in rabbits; regeneration of $\mathrm{B}$ cells appears within a month (Katsumata et al., 1993, Szkudelski, 2001, Eliziane et al., 2003).

\section{Collection of blood sample:}

Blood samples were taken from rabbit ear vein of fasting and postprandial animals. Samples were collected immediately before and daily after induction of diabetes..

For testing drug effect, samples were collected immediately before and 1, 2, 3, 4, 5, 24, 48 hours after administration of the drug. For daily testing of drug and drug combination effects, blood samples were collected 3 hours after food and drug administration. Blood glucose level was determined using a portable glucose analyzer (Katsumata et al., 1993 , Szkudelski, 2001). Blood glucose lowering activity in rabbits was done according to the method described by Gerhard Vogel (2002).

\section{Statistics:}

Results are presented as means \pm standards error of means (SEM). Statistical significance was calculated by one tailed Student's " $\mathrm{t}$ " test. $\mathrm{P}<0.005$ was considered significant.

\section{Results}

1- The effect of alloxan on blood glucose level of control non-treated rabbits:

Blood glucose level of control nontreated rabbits was $(4.79 \pm 0.26) \mathrm{mmol}$ when measured 3 hours after fasting. Hyperglycemia was detected after administering alloxan intraperitonially in a dose of $100 \mathrm{mg} / \mathrm{kg}$ body weight repeated $2-3$ times, hypoglycemia was detected after 8-24 hours, doses were repeated after 2 days till hyperglycemia was detected (Szkudelski, 2001). There was a significant increase in the blood glucose level. The blood glucose levels were $(25.47 \pm 2.52),(21.68 \pm 0.93)$ and $(19.20 \pm 1.19) \mathrm{mmol}$ on the $3 \mathrm{rd}, 10$ th and 17th day post alloxan administration, respectively (Figure 1). The increased blood glucose levels were all significant $(\mathrm{P}<0.05)$ compared to control non-treated rabbits.

2- The effect of different doses of gatifloxacin on blood glucose level of normal control animals and 10 day postalloxan administration :

The effect of different doses of gatifloxacin on the blood glucose level of normal animals was studied. The results showed that, gatifloxacin when given daily for 7 successive days (for the 3 animal groups) in the following doses 20,40, and 80 $\mathrm{mg} / \mathrm{kg} /$ body weight, it induced a significant decrease in blood glucose level from (4.79 $\pm 0.26) \mathrm{mmol}$ (non-treated) to $(4.30 \pm 0.28)$, $(4.02 .75 \pm 0.13)$ and $(3.81 \pm 0.21) \mathrm{mmol}$, respectively. $\mathrm{P}$ value was $<0.05$ in all the dose levels used (Fig.2). 


\section{Hypoglycemic Effet Of Some Fluoroquinolones On........}

Gatifloxacin administration, in a dose of $40 \mathrm{mg} / \mathrm{kg}$ body weight, to alloxan diabetic animals starting from the 10th day postalloxan administration and for 7 successive days, produced a little but significant hypoglycemia. Blood glucose level was $(19.20 \pm 1.19) \mathrm{mmol}$, while the alloxan treated blood glucose level was (21.68 \pm 0.93) mmol blood $(\mathrm{p}<0.05)$ (Fig. 5), However, the combined therapy of glimepiride (1.3 mg/kg body weight) and gatifloxacin $(40 \mathrm{mg} / \mathrm{kg} /$ body weight) for 7 successive days starting from the 10hㅡ day post alloxan administration produced a significant lowering of the blood glucose level from $(21.68 \pm 0.93) \mathrm{mmol}$ to $(7.9 \pm$ 0.37) mmol blood $(\mathrm{P}<0.01)$ (Fig. 5). While, combined therapy of metformin $(80 \mathrm{mg} / \mathrm{Kg}$ body weight/ day) for 7 successive days starting from the 10th day post alloxan administration produced a significant and more potent effect, from $(21.68 \pm 0.93)$ mmol to $(6.6 \pm 0.36)$ mmol $(\mathrm{P}<0.01)$ (Figure $7)$. There was significant lowering of blood glucose for metformin $(6.6 \pm 0.36) \mathrm{mmol}$ over glimepiride $(7.9 \pm 0.37) \mathrm{mmol}(\mathrm{P}<0.01)$, with the mentioned drug combinations

3- The effect of glimepiride on blood glucose level of normal control (nontreated) and alloxan diabetic rabbits:

Glimepiride was given orally in a dose of $1.3 \mathrm{mg} / \mathrm{kg}$ body weight twice daily for 7 successive days to both normal and alloxanized animals starting from the 10th day post-alloxan injection. The results showed significant decrease in the blood glucose level of control animals from (4.79 $\pm 0.26) \mathrm{mmol}$ to $(3.65 \pm 0.23) \mathrm{mmol}$ blood $(\mathrm{P}$ $<0.05)$, Also, the alloxanized animals showed significant decrease in the blood glucose level from $(21.68 \pm 0.93) \mathrm{mmol}$ to $(10.68 \pm 0.69)$ mmol $(\mathrm{P}<0.05)$ (Figure 3$)$.

\section{4- The effect of rosiglitazone on blood} glucose level of normal control (nontreated) and alloxan diabetic rabbits:

Rosiglitazone was given orally in a dose of $1.3 \mathrm{mg} / \mathrm{kg}$ body weight once a day for 7 successive days to both normal and alloxanized animals starting from the 10h day post-alloxan injection. The results showed significant decrease in the blood glucose level of control animals from (4.79 $\pm 0.26) \mathrm{mmol}$ to $(4.26 \pm 0.22) \mathrm{mmol}$ blood $(\mathrm{P}$ $<0.05$ ) (Figure 3), Also, the alloxanized animals showed significant decrease in the blood glucose level from (21.54 \pm 0.84$)$ mmol to $(13.37 \pm 2.35)$ mmol $(\mathrm{P}<0.05)$ ( Figure 4).

\section{5- The effect of gatifloxacin in combination} with glimepiride and rosiglitazone: on blood glucose level of normal control (non-treated) and the alloxan diabetic rabbits:

Gatifloxacin was given orally in a dose of $40 \mathrm{mg} / \mathrm{kg}$ body weight once a day for 7 successive days to both normal and alloxanized animals starting from the 10th day post-alloxan injection. The results showed significant decrease in the blood glucose level of control animals from $(4.79 \pm 0.26) \mathrm{mmol}$ to $(4.02 \pm 0.13)$ mmol blood $(\mathrm{P}<0.05)$ (Fig. 2). Also, the alloxanized animals showed significant decrease in the blood glucose level from $(21.68 \pm 0.93) \mathrm{mmol}$ to $(19.58 \pm 0.40)$ mmol blood ( $\mathrm{P}<0.05)$ (Figure 5).

Gatifloxacin given in dose of $40 \mathrm{mg} / \mathrm{kg}$ body weight once a day plus glimepiride (1.3 $\mathrm{mg} / \mathrm{kg}$ body weight twice a day for 7 successive days) to alloxanized animals starting from the 10hㅡ day post-alloxan injection resulted in significant decrease in blood glucose level from $(21.68 \pm 0.93)$ mmol to $(7.90 \pm 0.37)$ mmol $(\mathrm{P}<0.01)$ (Figure 5).

The previous drug combination plus rosiglitazone $(0.6 \mathrm{mg} / \mathrm{kg}$ body weight once a day for 7 successive days) to alloxanized animals resulted in significant decrease in blood glucose level from $(21.68 \pm 0.93)$ mmol to $(6.42 \pm 0.39)$ mmol $(\mathrm{P}<0.01)$ (Figure 5).

6- The effect of metformin on blood glucose level of normal control (nontreated) and the alloxan diabetic rabbits:

Metformin was given orally in a dose of $80 \mathrm{mg} / \mathrm{kg}$ body weight twice a day for 7 successive days to both normal and alloxanized animals starting from the 10h 
day post-alloxan injection. The results showed significant decrease in the blood glucose level of control rabbits from (4.79 $\pm 0.26) \mathrm{mmol}$ to $(3.81 \pm 0.16) \mathrm{mmol}(\mathrm{P}<0.01)$ (Fig. 3). Also, the alloxanized animals showed significant decrease in the blood glucose level from $(21.68 \pm 0.93) \mathrm{mmol}$ to (11.01.12 \pm 0.57$) \mathrm{mmol}(\mathrm{P}<0.01)$ (Figure 6).

7- The effect of gatifloxacin in combination with metformin and rosiglitazone on blood glucose level of normal control (non-treated) and the alloxan diabetic rabbits:

Gatifloxacin $(40 \mathrm{mg} / \mathrm{kg}$ b.w. once a day for 7 successive days to both normal and alloxanized animals) showed significant decrease in the blood glucose level of control animals from $(4.79 \pm 0.26) \mathrm{mmol}$ to $(4.02 \pm$ $0.13)$ mmol blood ( $\mathrm{P}<0.05)$ (Fig. 2), Also, the alloxanized animals showed significant decrease in the blood glucose level from $(21.68 \pm 0.93) \mathrm{mmol}$ to $(19.58 \pm 0.40) \mathrm{mmol}$ blood $(\mathrm{P}<0.05)$ (Figure 5).

Gatifloxacin given in adose of $40 \mathrm{mg} / \mathrm{kg}$ b.w. once a day plus Metformin given in dose of $80 \mathrm{mg} / \mathrm{kg}$ b.w. twice a day for 7 successive days to alloxanized animals, resulted in significant decrease in blood glucose level from $(21.68 \pm 0.93) \mathrm{mmol}$ to $(6.60 \pm 0.34)$ mmol blood $(\mathrm{P}<0.01)$ (Figure 7).

The previous drug combination plus rosiglitazone $0.6 \mathrm{mg} / \mathrm{kg}$ body weight once a day for 7 successive days to alloxanized animals resulted in significant decrease in blood glucose level from $(21.68 \pm 0.93)$ mmol to $(4.17 \pm 0.36) \mathrm{mmol}(\mathrm{P}<0.01)$ (Figure 7).

8- Insulin hypoglycemic effect in comparison to the effect of gatifloxacin on blood glucose level of normal control (non-treated) and alloxan diabetic rabbits in combination with glimepiride metformin and rosiglitazone:

Drug doses for 7 successive days to both normal and alloxanized animals starting from the 10th day post-alloxan injection showed the following: Gatifloxacin (40 $\mathrm{mg} / \mathrm{kg}$ b.w. once a day) resulted in significant decrease in the blood glucose level of control animals from $(4.79 \pm 0.26) \mathrm{mmol}$ to $(4.02 \pm$ $0.13)$ mmol ( $\mathrm{P}<0.05)$ (Fig. 2). Also, the alloxanized animals showed significant decrease in the blood glucose level from (21.68 \pm $0.93) \mathrm{mmol}$ to $(19.58 \pm 0.40) \mathrm{mmol}$ blood $(\mathrm{P}$ $<0.05$ ) (Figure 5). Gatifloxacin $(40 \mathrm{mg} / \mathrm{kg}$ b.w. once a day) plus glimepiride $(1.3 \mathrm{mg} / \mathrm{kg}$ b.w. twice a day) to alloxanized animals resulted in significant decrease in blood glucose level from $(21.68 \pm 0.93) \mathrm{mmol}$ to $(7.90 \pm 0.37) \mathrm{mg} / \mathrm{dL}$ blood $(\mathrm{P}<0.01)$ (Figure 5). The previous drug combination plus rosiglitazone $(0.6 \mathrm{mg} / \mathrm{kg}$ b.w. once a day) resulted in significant decrease in blood glucose level from $(21.68 \pm 0.93) \mathrm{mmol}$ to $(6.42 \pm 0.39) \mathrm{mmol}(\mathrm{P}<0.01)$ (Figure 5). Gatifloxacin (40 mg/kg b.w. once a day) plus metformin $(80 \mathrm{mg} / \mathrm{kg}$ b.w. twice a day) to alloxanized animals resulted in significant decrease in blood glucose level from $(21.68 \pm$ $0.93) \mathrm{mmol}$ to $(6.60 \pm 0.34) \mathrm{mmol}(\mathrm{P}<0.01)$ (Figure 7). The previous drug combination plus rosiglitazone $(0.6 \mathrm{mg} / \mathrm{kg}$ b.w. once a day) results in significant decrease in blood glucose level from $(21.68 \pm 0.93) \mathrm{mmol}$ to $(4.17 \pm 0.36) \mathrm{mmol}(\mathrm{P}<0.01)$ (Figure 7$)$. While insulin $(0.5 \mathrm{U} / \mathrm{Kg}$ b.w. a day) SC. injection (to alloxanized animals results in significant decrease in blood glucose level from $(21.68 \pm 0.93) \mathrm{mmol}$ to $(2.40 \pm 0.39)$ mmol $(\mathrm{P}<0.01)$ (Figure 8). 


\section{Hypoglycemic Effet Of Some Fluoroquinolones On........}

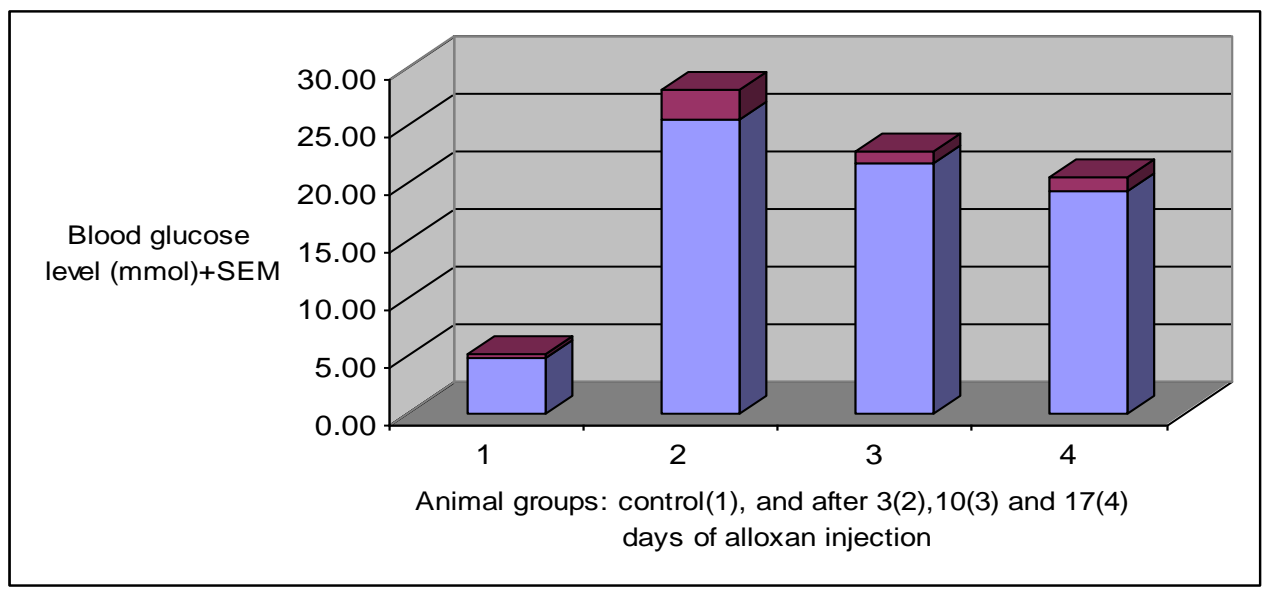

Figure1: Effect of alloxan (100 mg / kg b.w., IP repeated twice 2 days apart) on blood glucose level (mmol) in control rats and after 3,10 and 17 days of injection of alloxan.

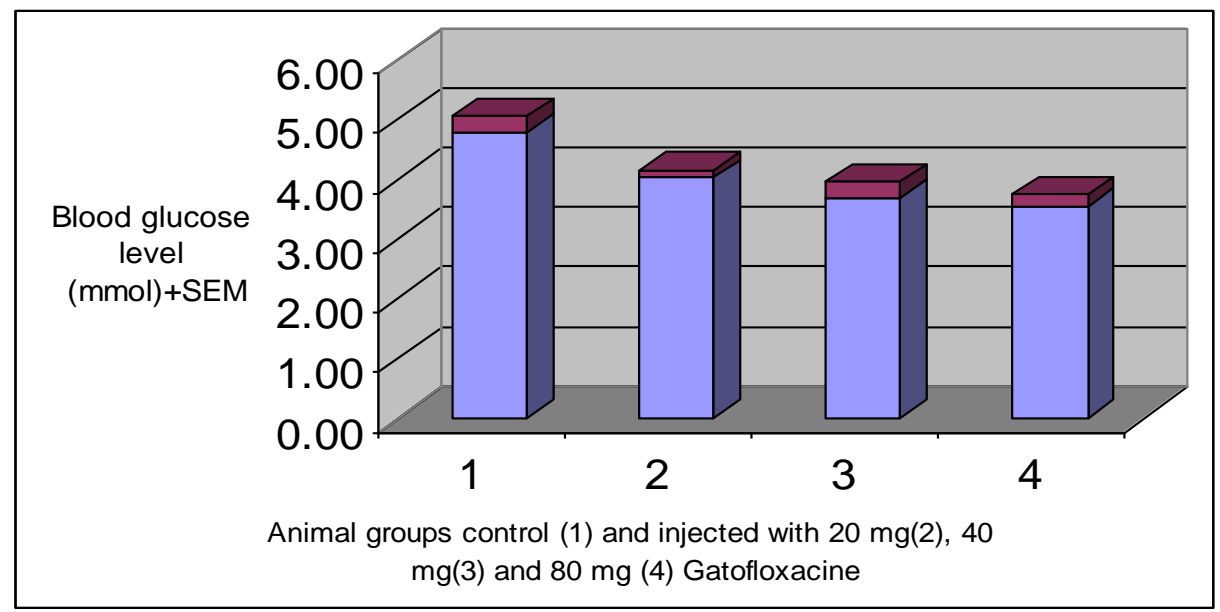

Figure2: Effect of different doses of gatifloxacin $(20 \mathrm{mg}, 40 \mathrm{mg}$ and $80 \mathrm{mg} / \mathrm{kg} \mathrm{b.w.})$ for 7 successive days on blood glucose level (mmol) of control (non-alloxan treated) animals

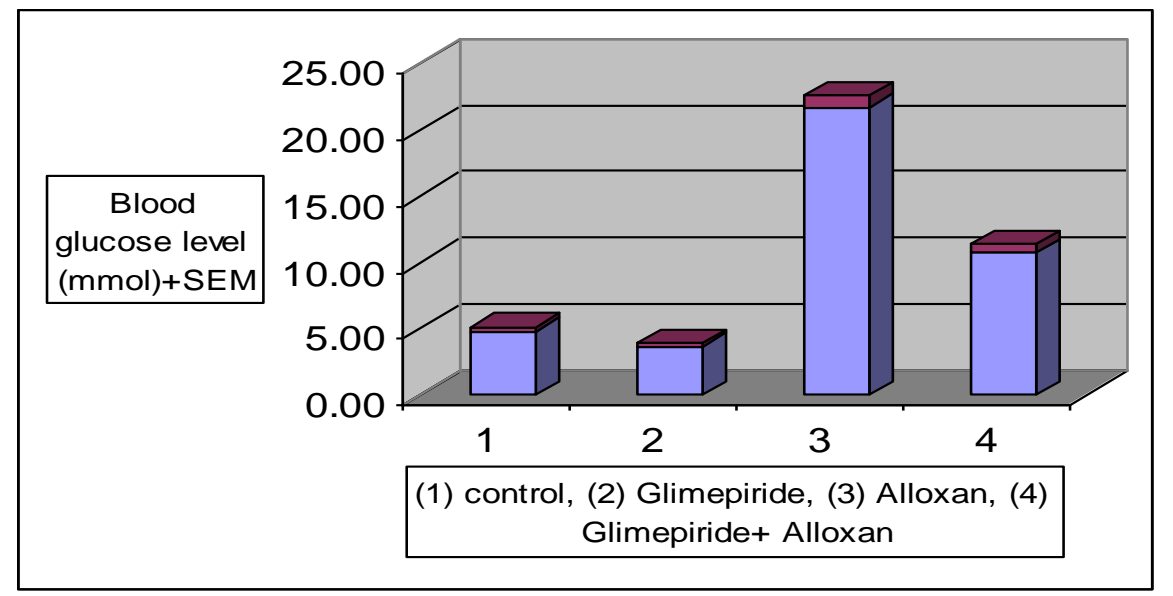

Figure 3: Effect of glimepiride $1.3 \mathrm{mg} / \mathrm{kg}$ b.w. twice daily orally for 7 successive days on blood glucose level mmol) of control (non-treated) and alloxan diabetic rats (10days). 


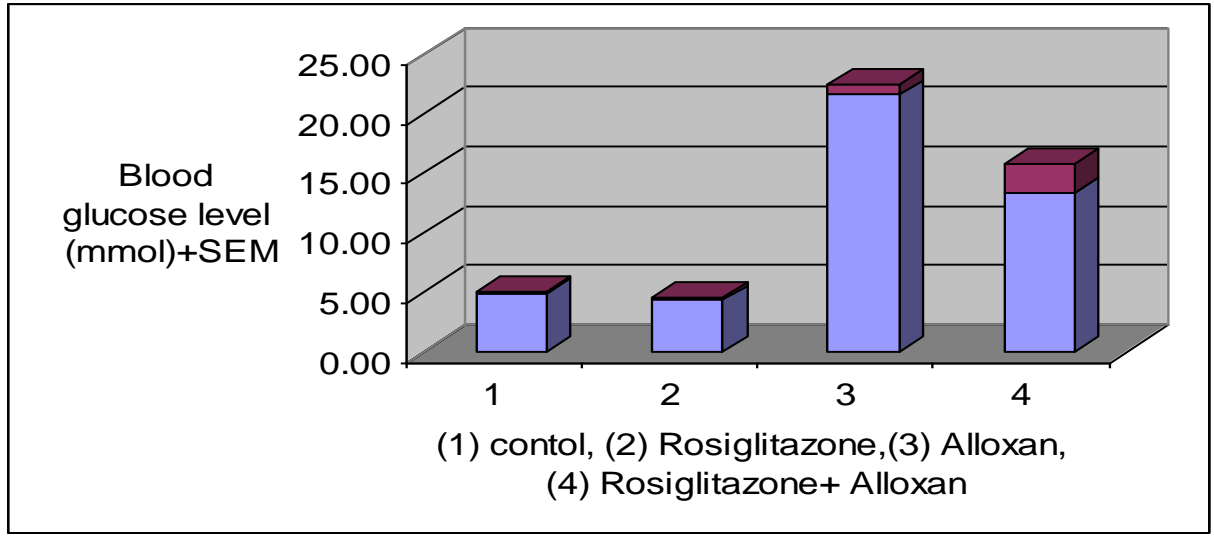

Figure 4: Effect of rosiglitazone $1.3 \mathrm{mg} / \mathrm{kg} \mathrm{b.w}$. a day orally for 7 successive days on blood glucose level (mmol) of control (non-treated) and alloxan diabetic rats (10days).

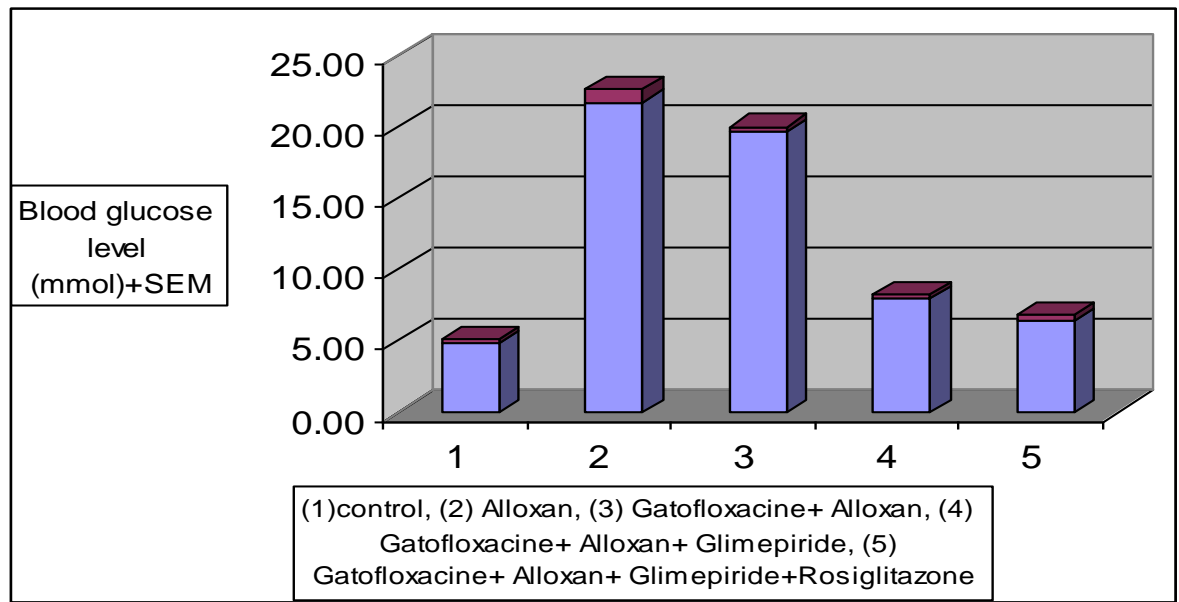

Figure 5: Effect of gatifloxacin (40 mg / $\mathrm{kg}$ b.w.) for 7 successive days on blood glucose level (mmol) of control (non-treated) and alloxan treated diabetic rats (10 days) and diabetic rats treated by glimepiride $1.3 \mathrm{mg} / \mathrm{kg}$ b.w. twice daily and rosiglitazone $1.3 \mathrm{mg} / \mathrm{kg} \mathrm{b.w}$. once daily orally for 7 successive days

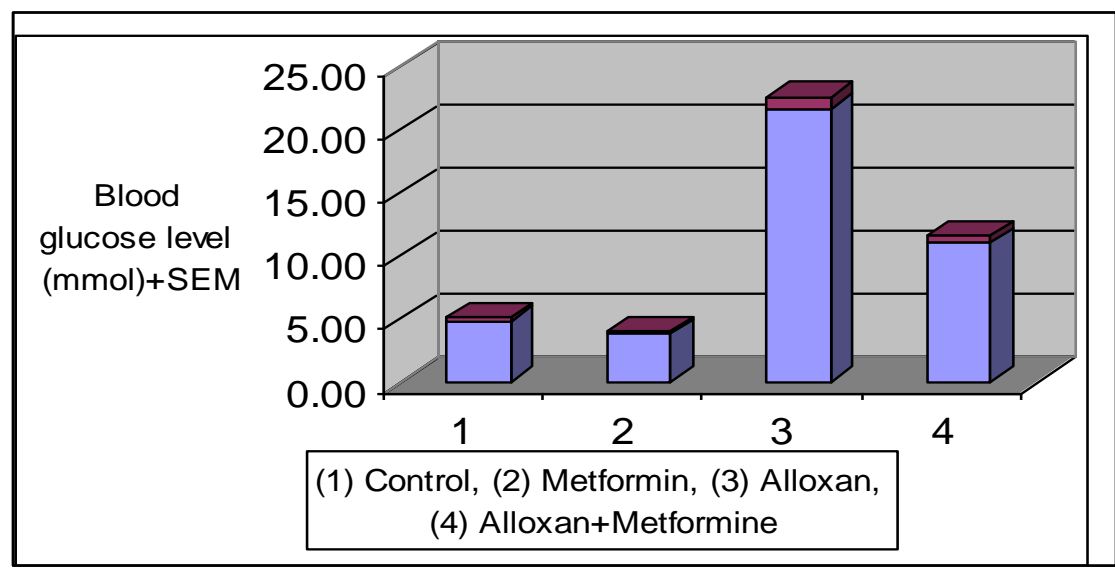

Figure 6: Effect of metformin $80 \mathrm{mg} / \mathrm{kg} \mathrm{b.w.} \mathrm{twice} \mathrm{a} \mathrm{day} \mathrm{orally} \mathrm{for} 7$ successive days on blood glucose level (mmol) of control (non-treated) and alloxan diabetic rats (10days). 


\section{Hypoglycemic Effet Of Some Fluoroquinolones On........}

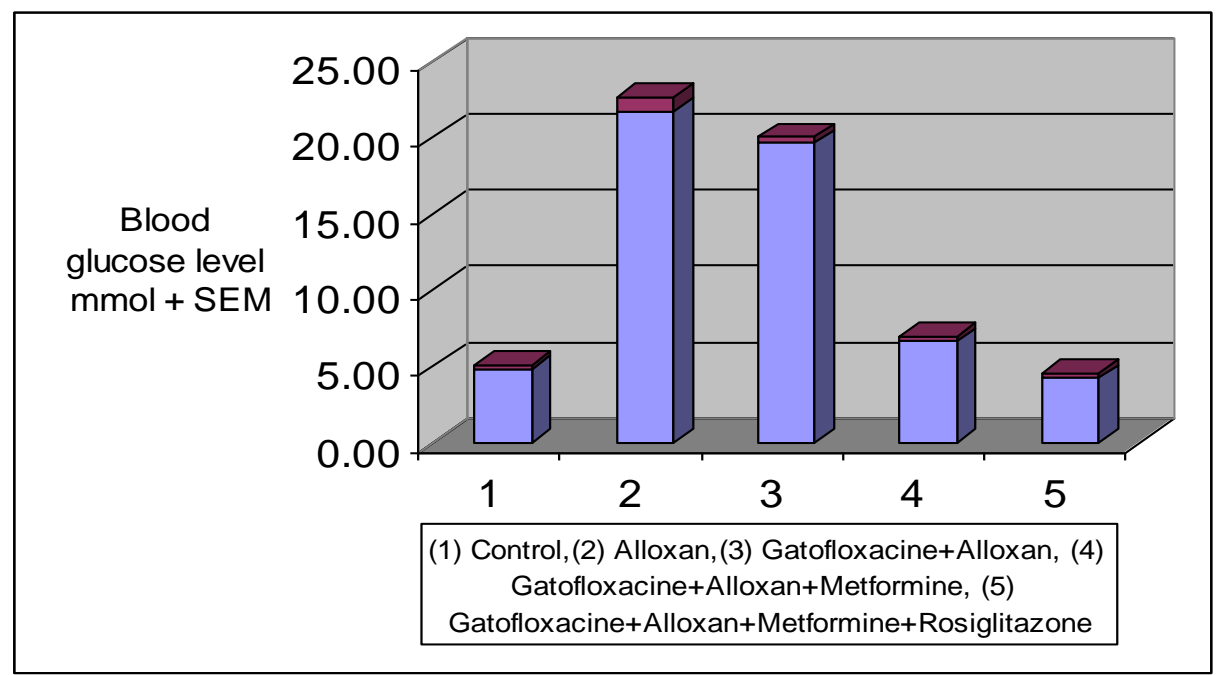

Figure 7: Effect of gatifloxacin (40 mg / kg b.w. daily) for 7 successive days on blood glucose level (mmol) of control (non-treated) and alloxan treated diabetic rats (10 days) and diabetic rats treated by metformin $(80 \mathrm{mg} / \mathrm{Kg}$ b.w. twice a day) and rosiglitazone $(0.6 \mathrm{mg} / \mathrm{Kg}$ b.w./day) orally for 7 successive days.

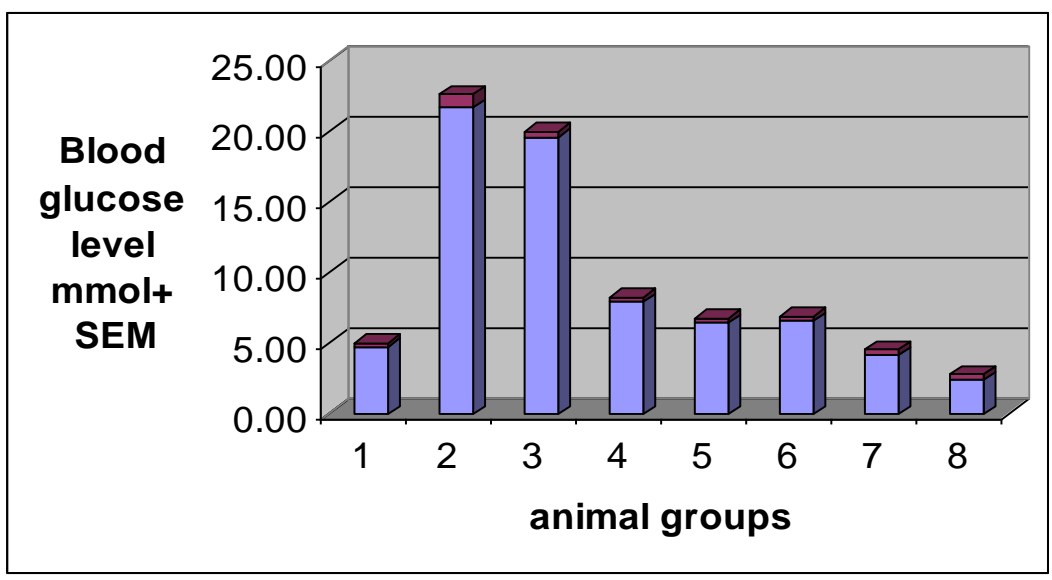

Figure 8: Effect of oral hypoglycemics Metformin $(80 \mathrm{mg} / \mathrm{Kg}$ b.w. twice a day) and Rosiglitazone $(0.6 \mathrm{mg} / \mathrm{Kg}$ b.w./day) orally for 7 successive days Glimepiride $1.3 \mathrm{mg} / \mathrm{kg}$ b.w. twice daily and Gatifloxacin (40 mg / kg b.w. daily) orally for 7 successive days compared to $\mathrm{SC}$ insulin $0.5 \mathrm{U} / \mathrm{Kg}$ on blood glucose level (mmol).

Animal groups: (1) Control (2) Alloxan (3) Gatifloxacin + alloxan (4) Gatifloxacin + alloxan + Glimepiride (5) Gatifloxacin + alloxan + Glimepiride Rosiglitazone Gatifloxacin + alloxan + Metformin (7) Gatifloxacin + alloxan + Metformin + Rosiglitazone (8) insulin

\section{Discussion}

Hypoglycemic episodes in patients with diabetes often go unrecognized, and over time, patients may lose the ability to sense hypoglycemia, increasing their risk. Intensive control of diabetes is beneficial for patients with diabetes, but it increases the risk of hypoglycemia, underscoring the complexity of diabetes management (Gabriely and Shamoon , 2004).

Diabetes is largely responsible for increased coronary artery, cerebrovascular and peripheral vascular disease, blindness, 
amputations and end stage renal disease in the developed world. Because of this, it is important to recognize and treat this devastating disease early in its progression to postpone or even prevent the serious complications associated with it (Wright et al., 2006) .

The combined therapy of oral hypoglycemics and antimicrobials is a very common one, as some diabetics under control are subjected to infection and are in need for its administration (Stallman and Lode ,2003).

Hypoglycemia is the limiting factor in the management of diabetes and a barrier to true glycemic control and becomes a progressively frequent clinical problem in advanced type 2 diabetes mellitus. As patients approach the insulin-deficient end of the spectrum of type 2, hypoglycemia results from the interplay of therapeutic insulin excess and compromised physiologic and behavioral defenses against falling plasma glucose concentrations. By practicing hypoglycemia risk reduction, applying the principles of aggressive glycemic therapy, it is possible to minimize the risk of hypoglycemia and improve glycemic control. Nonetheless, people with diabetes need better treatment regimens (Banarer and Cryer, 2004).

In the present study, diabetes was induced in rabbits by alloxan in a dose of $100 \mathrm{mg} / \mathrm{kg}$ body weight in repeated doses to produce type 2 diabetes (Covington et al.,1993), as rabbits are considered a good model for diabetes mellitus (Gerhard Vogel, 2002).

The blood glucose level was estimated by the procedure of Gruppuso et al,(1990) which is a chemical method. It has the advantage over other methods that it can estimate the blood glucose in the whole blood with the avoidance of the problem of haemolysis which is usually encountered with the animals blood sampling (Gruppuso et al., 1990)

Blood glucose level of control nontreated rabbits was $(4.79 \pm 0.26) \mathrm{mmol}$. After alloxan administration there was a significant increase in the blood glucose to $(25.47 \pm$ $2.52),(21.68 \pm 0.93)$ and $(19.20 \pm 1.19)$ on the $3 \underline{\mathrm{rd}}, 10$ th and $17 \underline{\text { th }}$ day respectively (Figure 1). The increased blood glucose level was significant with all measurements $(\mathrm{P}<$ 0.05). The action of alloxan on the pancreas is preceded by its rapid uptake by the B cells (Boquist et al., 1983). Rapid uptake by insulin-secreting cells has been proposed to be one of the important features determining alloxan diabetogenicity. Another aspect concerns the formation of reactive oxygen. A similar uptake of alloxan also takes place in the liver. However, the liver and other tissues are more resistant to reactive oxygen species in comparison to pancreatic B cells and this resistance protects them against alloxan toxicity (Tiedge et al., 1997 ; Szkudelski, 2001)

Glimepiride blocks both B-cells and cardiac cloned $\mathrm{K}_{\text {ATP }}$ channels with high affinity, since $\mathrm{K}_{\mathrm{ATP}}$ channels are found in a wide variety of extra pancreatic tissues (cardiac, skeletal muscle, smooth muscle and neurons) and benzamido-binding site (SUE1 and SUR2A), these might have greater therapeutic value in type II diabetes than sulfonylureas that interact with SUR1 only e.g. tolbutamide (Frances and Fiona, 2000). Glimepiride administration in a dose of 1.3 $\mathrm{mg} / \mathrm{kg}$. body weight orally twice daily for 7 successive days from the $10^{\text {th }}$ day postalloxan injection, induced a significant decrease in the hyperglycemic state from $(21.68+0.93)$ to $(10.68 \pm 0.69) \mathrm{mmol}(\mathrm{P}$ 0.01 ), although, it causes about $50 \%$ decrease in blood glucose level, it still not enough for the desired control of blood glucose. In nonalloxan treated animals, blood glucose level was also decreased from $(4.79+0.26)$ to $(3.65$ \pm 0.23 ) mmol, (P 0.01) (Figure 3) for the same effect on pancreatic and extra pancreatic tissues.

Fluoroquinolones are used widely in the treatment of various infectious diseases; some of the drugs are known to cause hypoglycemia as a side-effect. The effects of three fluoroquinolone derivatives, levoflo-xacin, gatifloxacin, and temafloxacin on insulin secretion and pancreatic beta-cell ATPsensitive $\mathrm{K}(+)$ channel it was found that they ininhibit the K(ATP) channel activity. While levofloxacin had only a small effect on 


\section{Hypoglycemic Effet Of Some Fluoroquinolones On........}

insulin secretion and K (ATP) currents, gatifloxacin and temafloxacin stimulated insulin secretion and inhibited K (ATP) channel currents in a dose-dependent manner. The site of action of gatifloxacin and temafloxacin on the K (ATP) channel was determined. In a reconstituted system, gatifloxacin and temafloxacin inhibited Kir6.2 Delta C26 channels, which function in the absence of the SUR subunit, indicating direct action of the drugs on the Kir6.2 subunits. These results suggest that stimulation of insulin secretion by inhibition of pancreatic beta-cell K (ATP) channels underlies the hypoglycemia caused by certain fluoroquinolones (Saraya et al., 2004).

Gatifloxacin and Moxifloxacin when given daily for 7 successive days in the following doses 20,40 , and $80 \mathrm{mg} / \mathrm{kg} /$ body weight, they induced a significant decrease in blood glucose level from $(4.79 \pm 0.26) \mathrm{mmol}$ to $(4.30 \pm 0.28),(4.02 .75 \pm 0.13)$ and $(3.81 \pm$ $0.21)$ mmol blood respectively. $P$ value was $<0.05$ in all the dose levels of the used antibiotics (Fig.2).

Gatifloxacin and moxifloxacin administration produced a little but significant hypoglycemia. Blood glucose level was $(19.20 \pm 1.19) \mathrm{mmol}$ while the alloxan treated blood glucose level was $(21.68 \pm 0.93) \mathrm{mmol}$ $(\mathrm{p}<0.05)$ (Fig. 5), However, the combined therapy of glimepiride and gatifloxacin produced a significant lowering of the blood glucose level from $(21.68 \pm 0.93) \mathrm{mmol}$ to $(7.9 \pm 0.37)$ mmol $(\mathrm{P}<0.01)$ (Figure 5). While, glimepiride combined therapy with metformin produced a significant and more potent lowering of the blood glucose level from $(21.68 \pm 0.93) \mathrm{mmol}$ blood to $(6.6 \pm$ $0.36)$ mmol blood $(\mathrm{P}<0.01)$ (Figure 7). The hypoglycemic effect of metformin was more potent than that of glimepiride with the mentioned drug doses in the mentioned combinations (see Fig. 7).

The incidence of specific adverse events associated with individual fluoroquinolones was reviewed in a five-year post-marketing surveillance (PMS) study in Japan, in which a total adverse drug reaction (ADR) rate of $1.3 \%$ was found for levofloxacin, compared to total $\mathrm{ADR}$ rates of $3.3 \%$ for pazufloxacin,
$3.6 \%$ for tosufloxacin, $4.5 \%$ for gatifloxacin and $5.4 \%$ for balofloxacin. Levofloxacin had the lowest rate of CNS effects and skin adverse effects among the agents studded. (Rubinstein, 2001)

The hypoglycemic effect of rosiglitazone given in dose used to both normal and alloxanized animals resulted in significant decrease in the blood glucose level of control animals from $(4.79 \pm 0.26) \mathrm{mmol}$ to $(4.26 \pm$ $0.22)$ mmol $(\mathrm{P}<0.05)$ (Table 3), Also, the alloxanized animals showed significant decrease in the blood glucose level from $(21.54 \pm$ $0.84) \mathrm{mmol}$ to $(13.37 \pm 2.35) \mathrm{mmol}(\mathrm{P}<0.05)$ (Figure 4).

Rosiglitazone is a pure ligand of PPAR $\gamma$, and has no PPAR $\alpha$ - binding action. Apart from its effect on insulin resistance, it appears to have an anti-inflammatory effect (Mohandy et al., 2004). The nuclear receptor family of PPARs was named for the ability of the original member to induce hepatic peroxisome proliferation in mice in response to xenobiotic stimuli. However, studies on the action and structure of the 3 human PPAR isotypes (PPAR $\alpha, \operatorname{PPAR} \delta$, and PPAR $\gamma$ ) suggest that these moieties are intimately involved in nutrient sensing and the regulation of carbohydrate and lipid metabolism. PPAR $\alpha$ and PPAR $\delta$ appear primarily to stimulate oxidative lipid metabolism, while PPAR $\gamma$ is principally involved in the cellular assimilation of lipids via anabolic pathways Robert et al., (2006).

Metformin produced significant decrease in the blood glucose level of control rabbits from $(4.79 \pm 0.26) \mathrm{mmol}$ to $(3.81 \pm$ 0.16) mmol blood ( $\mathrm{P}<0.01)$ (Fig. 3), Also, the alloxanized animals showed significant decrease in the blood glucose level from $(21.68 \pm 0.93) \mathrm{mmol}$ to $(11.01 .12 \pm 0.57)$ mmol blood (P <0.01) (Figure 6).

AMP-activated protein kinase (AMPK) is an enzyme that works as a fuel gauge which becomes activated in situations of energy consumption. AMPK is involved in the mechanism of action of metformin and thiozolidinediones, and the adipocytokines leptin and adiponectin. These data, along with evidence that pharmacological activation of AMPK in vivo improves blood glucose 
homeostasis, (Schimmack et al., 2006). AMP kinase pathway activation by metformin, recently shown to be necessary for metformin inhibition of gluconeogenesis in hepatocytes, is also involved in metformin-induced growth inhibition of epithelial cells. The growth inhibition was associated with decreased mammalian target of rapamycin and S6 kinase activation and a general decrease in mRNA translation. These results provide evidence for a mechanism that may contribute to the antineoplastic effects of Metformin suggested by (Zakikhani et al., 2006).

Metformin plus gatifloxacin given for 7 successive days to alloxanized animals resulted in significant decrease in blood glucose level from $(21.68 \pm 0.93) \mathrm{mmol}$ to $(6.60 \pm 0.34) \mathrm{mmol}(\mathrm{P}<0.01)$ (Figure 7). The previous drug combination plus rosiglitazone resulted in significant decrease in blood glucose level from $(21.68 \pm 0.93) \mathrm{mmol}$ to $(4.17 \pm 0.36) \mathrm{mmol}(\mathrm{P}<0.01)$ (Figure 7).

Garber et al., (2006) showed that metformin-glibenclamide tablets resulted in significantly greater reductions in $\mathrm{HbA1C}$ ($1.5 \%)$ and fasting plasma glucose [-2.6 $\mathrm{mmol} / \mathrm{l}(-46 \mathrm{mg} / \mathrm{dl})]$ than metformin plus rosiglitazone $[-1.1 \%, \mathrm{p}<0.001 ;-2 \mathrm{mmol} / \mathrm{l}$ ($36 \mathrm{mg} / \mathrm{dl}), \mathrm{p}=0.03]$. More patients receiving metformin-glibenclamide attained $\mathrm{HbA1C}$ $<7.0 \%$ than did those in the metformin plus rosiglitazone group (60 vs. 47\%) and had fasting plasma glucose levels $<7 \mathrm{mmol} / \mathrm{l}$ $(<126 \mathrm{mg} / \mathrm{dl})$ by week 24 (34 vs. 25\%) (Garber et al., 2006)

Insulin $(0.5 \mathrm{U} / \mathrm{Kg}$ b.w. a day) SC. injection (to alloxanized animals resulted in significant decrease in blood glucose level from $(21.68 \pm 0.93) \mathrm{mmol}$ to $(2.40 \pm 0.39)$ mmol ( $\mathrm{P}<0.01)$ (Figure 8).

The results may also be explained by the study of Bruce et al., (2006) that evaluated the mechanism of action of metformin-glibenclamide combination tablets (Glucovance) vs. metformin and glibenclamide in 50 type 2 diabetes patients inadequately controlled by diet and exercise. A glycaemic target of $\mathrm{HbA1C} 7.0 \%$ was used. Final $\mathrm{HbA}(1 \mathrm{C})$, fasting glucose and post-oral glucose tolerance test (OGTT) blood glucose levels were similar between groups, although average doses of metformin and glibenclamide from combination tablets (708 and $3.5 \mathrm{mg}$ ) were lower than monotherapy doses (1500 and $6.6 \mathrm{mg}$ ). Second-phase insulin during a hyperglycaemic clamp increased by $93 \%$ with combination tablets, $36 \%$ with metformin and $46 \%$ with glibenclamide. The insulin response post- oral glucose tolerance test was more rapid with the combination tablets vs. glibenclamide. First-phase insulin responses improved modestly in all groups, possibly due to reduced glucotoxicity. Changes in insulin sensitivity were minor. Larger betacell responses between combination tablets and glibenclamide may reflect more rapid glibenclamide absorption.

\section{Conclusion}

As hypoglycemia is the limiting factor in the glycemic management of diabetes and a barrier to true glycemic control, frequent clinical problems in advanced type 2 diabetes mellitus are progressively encountered. Hypoglycemia results from the interplay of therapeutic agents. By practicing hypoglycemia risk reduction, applying the principles of aggressive glycemic therapy, and considering conventional risk factors and those indicative of compromised glucose counterregulation, it is possible to minimize the risk of hypoglycemia and improve glycemic control. Nonetheless, people with diabetes need better treatment regimens. The present study shows that gatifloxacin and moxifloxacin lower blood glucose level in healthy and alloxan induced diabetic rabbits. Also, these drugs augment the blood glucose lowering effect of glimeperide, rosiglitazone, and metformin. The drug combinations had synergistic hypoglycemic effect that was potentiated by gatifloxacin and moxifloxacin

\section{References}

1. Baker SE Hangii MC (2002): Possible Gatifloxacin-induced hypoglycemia. Ann. Pharmacother., 2002; 36(11):1722- 1726

2. Banarer $S$ and Cryer PE (2004): Hypoglycemia in type 2 diabetes. Med Clin North Am., 2004;88(4):1107-16, 


\section{Hypoglycemic Effet Of Some Fluoroquinolones On........}

3. Bansal R, Ahmad N, Kidwai JR (1980): Alloxan-glucose interaction: effect of incorporation of 14C-leucine into pancreatic islets of rats. Acta. Diabetol. Lat., 17: 135143, 1980.

4. Basaria S, Braga M and Moore WT (2002): Doxycycline-induced hypoglycemia in a nondiabetic young man. South Med. J., 2002; 95(11):1353-4

5. Brunova E, Slabochova Z, Platilova $\mathbf{H}$, Pavlik F, Grafnetterova J, Dvoracek K(1977).: Interaction of Tolbutamid and chloramphenicol in diabetic patients.

6. Int. J. Clin. Pharmaco.l Biopharm., 1977; 15(1):7-12.

7. Bruce S, Park JS, Fiedorek FT, Howlett HC (2006):Beta-cell response to metforminglibenclamide combination tablets (Glucovance) in patients with type 2 diabetes. Int J Clin Pract., 2006;60(7):783-90

8. Buse JB (2000): Pioglitazone in the treatment of type II diabetes mellitus; U.S. clinical experience. Exp. Clin. Endocrinol. Diabetes, 108(2000) suppl. 2: S250 - S255.

9. Bussing R and Gende A (2002): Severe Hypoglycemia From Clarithromycin-Sulfonylurea Drug Interaction Diabetes Care, 25: 1659-1661.

10. Covington DS, Xue H, Pizzini R, Lally K, Andrassy RJ.(1993): Streptozotocin and aloxan are comparable agents in the diabetic model of impaired wound healing. Diabetic Res., 1993;23: 47-53.

11. Ding SY, Shen ZF, Chen YT, Sun SJ, Liu Q (2005): Pioglitazone can ameliorate insulin resistance in low-dose streptozotocin and high sucrose-fat diet induced obese rats. Acta Pharmacologica Sinica., Volume 26 Issue 5 Page 575

12. Eliziane Nitz de Carvalho'; Nestor Antônio Schmidt de Carvalho ${ }^{\text {II }}$; Ferreira LM. (2003): Experimental model of induction of diabetes mellitus in rats. Acta Cir. Bras., vol.18 no.spe São Paulo 2003

13. Friedrich LV, Dougherty R (2004): Fatal hypoglycemia associated with levofloxacin. Pharmacotherapy, 2004; 24(12):1807-1812.

14. Frances M A, and Fiona MG (2000): Tissue specific effects of sulfonylureas lessons from studies of cloned $\mathrm{K}_{\mathrm{ATP}}$ channels. J. Diabetes and its Complications (Elsevier), 14 (2000) $192-196$.

15. Garber A, Klein E, Bruce $S$ and Mohideen P (2006): Metformin-gliben-clamide versus Metformin plus Rosiglitazone in patients with type 2 diabetes inadequately controlled on metformin monotherapy. Diabetes Obes Metab., 2006;8 (2): 156-63.

16. Gavin J R 3rd, Kubin R, Choudhri S, Kubitza D, Himmel H, Gross R, Meyer JM. (2004): Moxifloxacin and glucose homeostasis: a pooled-analysis of the evidence from clinical and post marketing studies. Drug. Saf., 2004; 27(9):671-86.

17. Gabriely I, Shamoon H (2004): Hypoglycemia in diabetes: common, often unrecognized.Cleve Clin J. Med., 2004; 71 (4): 33542.

18. Gerhard Vogel H (2002): Blood glucose lowering activity in rabbits. Drug Discovery and Evaluation, Second edition 2002, pp K.5.0.1. Springer New York.

19. Gruppuso PA, Boylan JM, Posner BI, Faure R, Brautigan DL (1990): Hepatic protein phosphotyrosine phosphatase. Dephosphorylation of insulin receptor and epidermal growth factor receptors in normal and alloxan diabetic rats. J Clin Invest., 85: 1754-1760.

20. Gunter Muller (2000): The molecular mechanism of the insulin-mimetic/ sensitizing activity of the antidiabetic sulfonylurea drug Amaryl (Glimepiride). Molecular Medicine, 6(11): 907-933.

21. Harrigan RA, Nathan MS, Beatti P (2001): Oral agents for the treatment of typeII diabetes mellitus: Pharmacology, toxicology and treatment. Ann. Emerg. Med., 38: 68-78.

22. Harrower AD (1999): Pharmacokinetics of oral antihyperglycemic agents in patients with renal insufficiency. Clin. Pharmacokinet., 31: $111-119$ \{Medline\}.

23. International Diabetes Federation. Diabetes e-Atlas. [July 14 2005]. Available at: www. Eatlas.idf.org

24. Katsumata K, Katsumata $\mathbf{Y}$, Ozawa T, Katsumata K, Jr (1993): Potentiation effect of combined usage of three sulfonylurea drugs on the occurrence of alloxan diabetes in rats. Horm. Metab. Res., 25:125126.

25. LeBlanc M, Belanger C, Cossette P.(2004): Severe and resistant hypoglycemia associated with concomitant Gatifloxacin and Glyburide therapy. Pharmacotherapy.,2004; 24(7):92631.

26. Mohanty P, Aljada A, Ghanim H, Hofmeyer D, Tripathy D, Sayed T, AlHaddad W, Dhindsa $S$ and Dandona $P$ 


\section{Amr Heshmat Rostom \& Ali Ibrahim Al-Sultan}

(2004): Evidence for a potent antiinflammatory effect of Rosiglitazone. J. Clin.

Endocrinol. Metab., 2004; 89: 2728 - 2735.

27. Niemi $M$, Neuvonen $\mathbf{P J}$ and Kivistok $\mathbf{T}$ (2001a): The cytochrome P450 3A4 inhibitor Clarithromycin increases the plasma concentration and effect of Repaglinide. Clin. Pharmacol. Therapeutics, 70(1): 58-65.

28. Niemi M, Backman JT, Neuvonen PJ and Kivistok T (2001b): Effects of rifampin on the pharmacokinetics and Pharmacodynamics of Glyburide and glipizide. Clin. Pharmacol. Therapeutics, 69: 400 - 406 \{Medline\}.

29. Ovali F, Samanci N, Sevinc E, Dagoglu T.(2004): Isoniazid and hypoglycemia in a premature infant. J. Paediatr. Child Health., 2004 ; 40(8):490-492.

30. Petrakis I, Chalkiadakis G, Vrachassotakis N, Sciacca V, Vassilakis S, Xynos E (1999): Induced-Hyperglycemia Attenuates Erythromycin -Induced Acceleration of hypertonic Liquid-Phase Gastric Emptying in Type-I Diabetic Patients. Digestive Diseases, 1999; 17: 241-247

31. Rizza R (2006): Daily 'polypill' could prevent 7.2 million deaths, disabled from diabetes. June 12, 2006 issue of USA Today, page 7D.

32. Robert K, Semple V, Krishna K, Chatterjee and Stephen O'Rahilly (2006): PPAR $\gamma$ and human metabolic disease. J Clin Invest., 2006 1; 116(3): 581-589.

33. Rubinstein E (2001): History of Quinolones and their side effects. Chemotherapy. 47 Suppl 3:3-8; discussion 44-48.

34. Saraya A, Yokokura M, Gonoi T, Seino S, (2004): Effects of fluoroquinolones on insulin secretion and beta-cell ATP-sensitive $\mathrm{K}+$ channels. European Journal of Pharmacology, 497(1):111-7.
35. Schimmack G, Defronzo RA, Musi N (2006): AMP-activated protein kinase: Role in metabolism and therapeutic implications. Diabetes Obes Metab., 2006;8(6):591-602

36. Stallman R, Lode H.(2003): Fluoroquinolones in the elderly: safety considerations. Drugs Aging., 2003; 20(4):289-302.

37. Szkudelski T, Kandulska K, Okulicz M. (1998): Alloxan in vivo does not only exert deleterious effects on pancreatic B cells. Physiol. Res., 47: 343-346, 1998.

38. Szkudelski T (2001): The Mechanism of Alloxan and Streptozotocin Action in B Cells of the Rat Pancreas. Physiol. Res.,50: 536546, 2001

39. World Health Organization: The World Health Bulletin, Geneva, Switzerland, June 1997.

40. World Health Organization: The World Health Report, Geneva, Switzerland, 1998.

41. Wright E Jr, Scism-Bacon JL, and Glass LC (2006): Oxidative stress in type 2 diabetes: the role of fasting and postprandial glycaemia Int J Clin Pract. 2006; 60(3): 308314.

42. Zakikhani M, Dowling R, Fantus IG, Sonenberg N, Pollak M (2006):Metformin is an AMP kinase-dependent growth inhibitor for breast cancer cells. Cancer Res., 2006 1;66(21):10269-73.

43. Zhou G, Myers R, Li Y, Chen Y, Shen X, Fenyk-Melody J, Wu M, Ventre J, Doebber T, Fujii N, Musi N, Hirshman M, Goodyear L, Moller D (2001). "Role of AMP-activated protein kinase in mechanism of metformin action."J. Clin. Invest., 108 (8): 1167-1174.

44. Zimmet $P$ (2003): The burden of type 2 diabetes: are we doing enough? Diabetes Metab., 2003; (4 pt 2): 6s9- 18. 


\section{انخفاض السكر فى الام من ثأثير الفلوروكينولونز

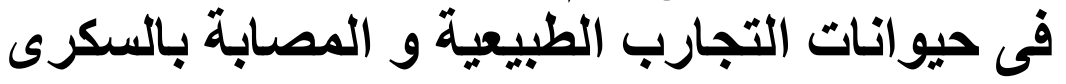

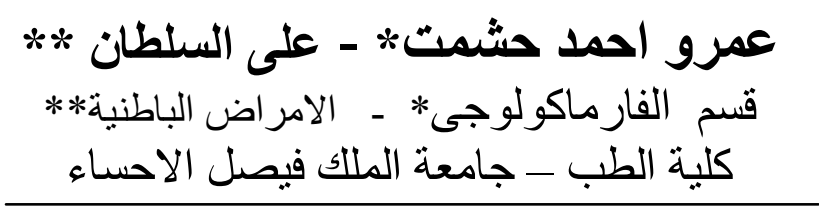

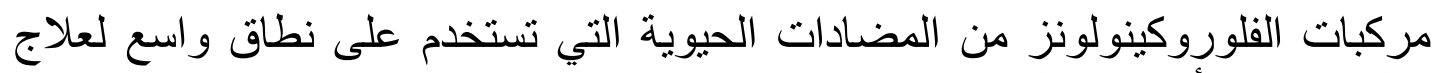

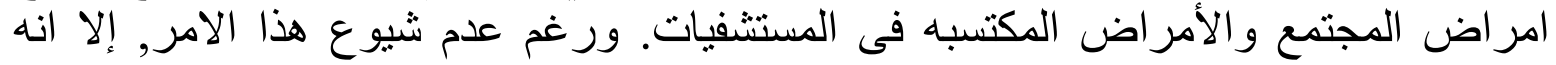

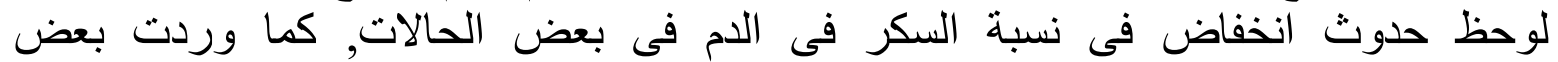

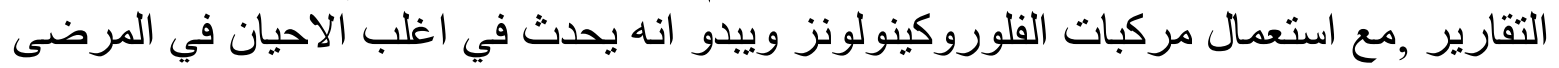

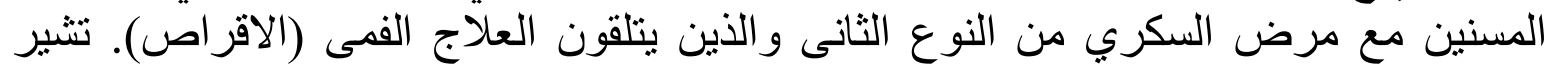

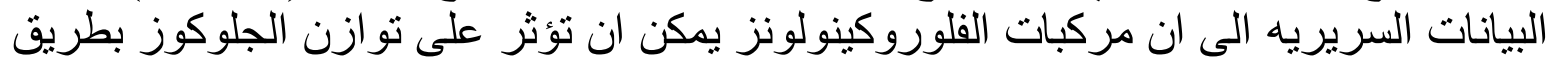

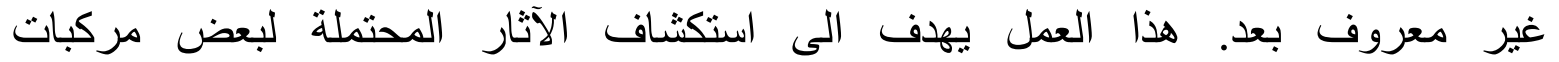

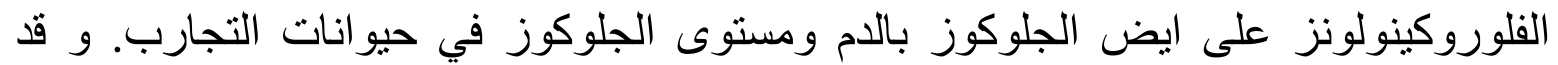

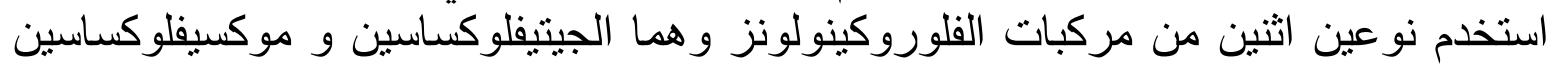

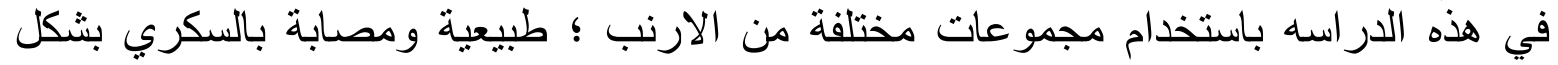
تجريبي. إعتبار ات السلامة كانت من الهمام الهم اهدفنا.

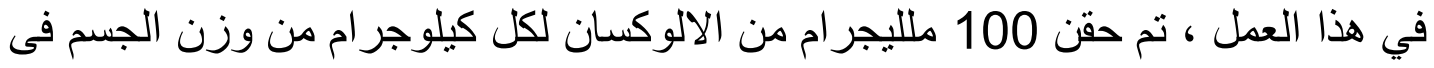

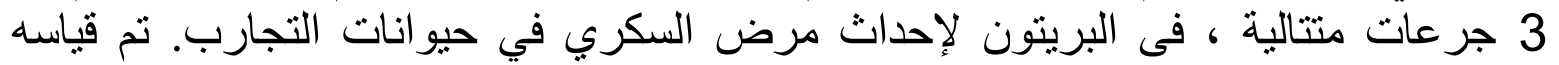

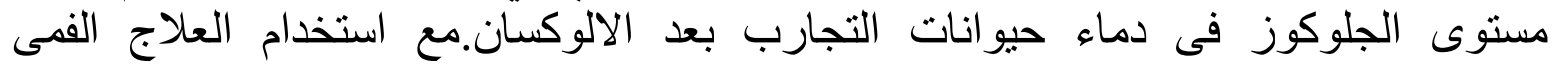

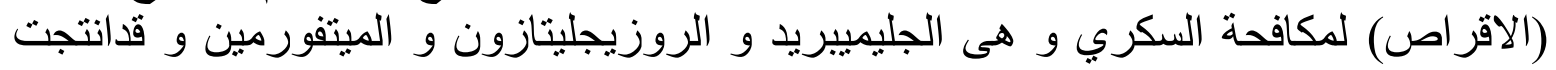

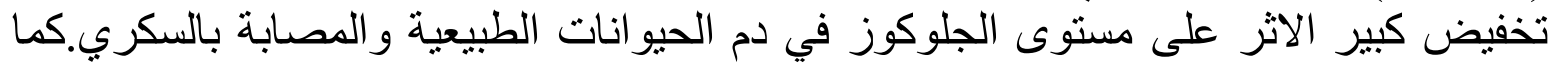

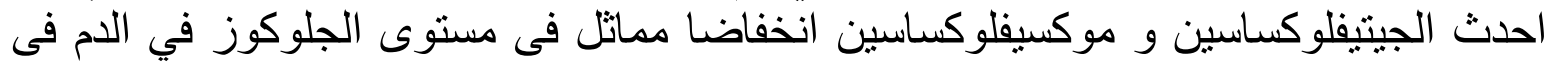

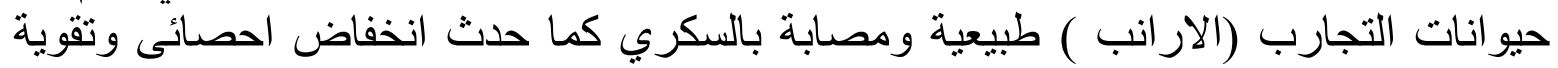

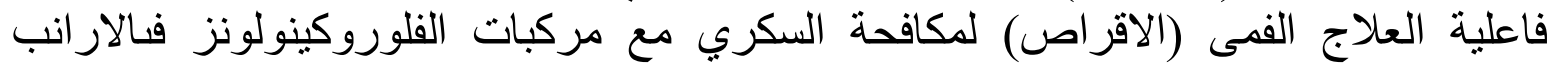
الطبيعية و المصابة بالسكري. 